\title{
Antimicrobial activity of cefepime and rifampicin in cerebrospinal fluid in vitro Richard Schwameis ${ }^{1}$, Robert Sauermann*1, Manfred Fille ${ }^{2}$, Maria L Camuz Ligios $^{1}$ and Markus Zeitlinger ${ }^{1}$
}

\author{
Address: ${ }^{1}$ Division of Molecular Pharmacokinetics and Imaging, Department of Clinical Pharmacology, Medical University of Vienna, 1090 \\ Vienna, Austria and 2Department of Hygiene, Microbiology and Social Medicine, Innsbruck Medical University, 6020 Innsbruck, Austria \\ Email: Robert Sauermann* - robert.sauermann@meduniwien.ac.at \\ * Corresponding author
}

from I4th Scientific Symposium of the Austrian Pharmacological Society (APHAR)

Innsbruck, Austria. 21-22 November 2008

Published: 5 November 2008

BMC Pharmacology 2008, 8(Suppl I):A56 doi:10.1 186/I47I-2210-8-SI-A56

This abstract is available from: http://www.biomedcentral.com/I47I-22I0/8/SI/A56

(C) 2008 Schwameis et al; licensee BioMed Central Ltd.

\section{Objectives}

Although antimicrobial agents are used for infections of the central nervous system (CNS), their pharmacodynamics is commonly evaluated only in commercially available bacterial growth media. It has been described that different media such as cerebrospinal fluid (CSF) may affect the activity of antibiotics $[1,2]$. Due to documented penetration into CSF, cefepime and rifampicin are used for treatment of CNS infections. In the present study, the effects of CSF on bacterial killing by these agents were investigated.

\section{Methods}

CSF was collected from over 150 patients without antibiotic therapy. The samples were pooled, stored at $-80^{\circ}$ and sterile-filtered before use. Time-kill curves of cefepime and rifampicin were performed over $24 \mathrm{~h}$ using drug concentrations of $0.25,0.5,1,2,4$ and 8 -fold the respective MIC for the Staphylococcus aureus ATCC 29213 strain. Killing curves were performed in Mueller-Hinton broth (MHB), in CSF incubated in ambient air $\left(\mathrm{CSF}_{\text {air }}\right)$ and in CSF in air with $5 \% \mathrm{CO}_{2}\left(\mathrm{CSF}_{\mathrm{CO} 2}\right) \cdot \mathrm{CO}_{2}$ was used to adjust the $\mathrm{pH}$ of CSF to physiological values as previously recommended [3].

\section{Results}

Bacterial growth in CSF was slower and less pronounced than in MHB resulting in bacterial counts that were $~ 10-$ fold lower in CSF than in MHB after overnight incubation.
However, sustained bacterial killing was achieved by cefepime at lower drug concentrations in $\mathrm{CSF}_{\mathrm{CO} 2}$ than in MHB. In contrast, rifampicin concentrations above the MIC were required to exert sustained killing in $\mathrm{CSF}_{\mathrm{CO} 2}$. Both drugs were least effective in $\mathrm{CSF}_{\mathrm{air}}$ due to the increase of the $\mathrm{pH}$ to 9-10 which is known to reduce the activity of both agents.

\section{Conclusion}

Standard susceptibility tests may lead to over- or underestimation of the activity of distinct antibiotics in CSF. Evaluation of the antimicrobial activity in $\mathrm{pH}$-adjusted CSF can provide helpful information on antibiotics considered for the treatment of bacterial infections residing in CSF.

\section{References}

I. Meng X, Pei Y, Nightingale C, Quintiliani R: Determination of the in vivo post-antibiotic effects of ciprofloxacin and rifampicin. J Antimicrob Chemother 1995, 36:987-996.

2. Zhanel G, Karlowsky J, Davidson R, Hoban D: Effect of pooled human cerebrospinal fluid on the postantibiotic effects of cefotaxime, ciprofloxacin, and gentamicin against Escherichia coli. Antimicrob Agents Chemother 1992, 36: I I 36- I I 39.

3. Cunniffe J, Whitby-Strevens S, Wilcox M: Effect of pH changes in cerebrospinal fluid specimens on bacterial survival and antigen test results. J Clin Pathol 1996, 49:249-253. 